University of Nebraska - Lincoln

DigitalCommons@University of Nebraska - Lincoln

2013

\title{
Validation of Noah-Simulated Soil Temperature in the North American Land Data Assimilation System Phase 2
}

Youlong Xia

I. M. Systems Group, Inc, youlong.xia@noaa.gov

Michael Ek

Environmental Modeling Center of National Centers for Environmental Prediction, ek@ucar.edu

Justin Sheffield

Princeton University, justin@princeton.edu

Ben Livneh

University of Washington

Maoyi Huang

Pacific Northwest National Laboratory

See next page for additional authors

Follow this and additional works at: https://digitalcommons.unl.edu/natrespapers

Part of the Natural Resources and Conservation Commons, Natural Resources Management and Policy Commons, and the Other Environmental Sciences Commons

Xia, Youlong; Ek, Michael; Sheffield, Justin; Livneh, Ben; Huang, Maoyi; Wei, Helin; Feng, Song; Luo, Lifeng; Meng, Jesse; and Wood, Eric, "Validation of Noah-Simulated Soil Temperature in the North American Land Data Assimilation System Phase 2" (2013). Papers in Natural Resources. 383.

https://digitalcommons.unl.edu/natrespapers/383

This Article is brought to you for free and open access by the Natural Resources, School of at DigitalCommons@University of Nebraska - Lincoln. It has been accepted for inclusion in Papers in Natural Resources by an authorized administrator of DigitalCommons@University of Nebraska - Lincoln. 


\section{Authors}

Youlong Xia, Michael Ek, Justin Sheffield, Ben Livneh, Maoyi Huang, Helin Wei, Song Feng, Lifeng Luo, Jesse Meng, and Eric Wood 


\title{
Validation of Noah-Simulated Soil Temperature in the North American Land Data Assimilation System Phase 2
}

\author{
Youlong XiA,,${ }^{,+}$Michael Ek, ${ }^{+}$Justin Sheffield, ${ }^{\#}$ Ben Livneh, ${ }^{@}$ MaOyi Huang, ${ }^{\&}$ Helin Wei,,${ }^{*}+$ \\ SONG FENG, ${ }^{* *}$ LIFENG LuO, ${ }^{++}$Jesse MENG, ${ }^{*+}{ }^{+}$AND ERIC WOOD ${ }^{\#}$ \\ * I. M. Systems Group, Inc., Camp Springs, Maryland \\ ${ }^{+}$Environmental Modeling Center of National Centers for Environmental Prediction, Camp Springs, Maryland \\ \# Department of Environmental and Civil Engineering, Princeton University, Princeton, New Jersey \\ ${ }^{@}$ Department of Environmental and Civil Engineering, University of Washington, Seattle, Washington \\ \& Pacific Northwest National Laboratory, Richland, Washington \\ ** School of Natural Resources, University of Nebraska-Lincoln, Lincoln, Nebraska \\ ${ }^{++}$Department of Geography, Michigan State University, East Lansing, Michigan
}

(Manuscript received 6 January 2012, in final form 27 June 2012)

\begin{abstract}
Soil temperature can exhibit considerable memory from weather and climate signals and is among the most important initial conditions in numerical weather and climate models. Consequently, a more accurate longterm land surface soil temperature dataset is needed to improve weather and climate simulation and prediction, and is also important for the simulation of agricultural crop yield and ecological processes. The North American Land Data Assimilation phase 2 (NLDAS-2) has generated 31 years (1979-2009) of simulated hourly soil temperature data with a spatial resolution of $1 / 8^{\circ}$. This dataset has not been comprehensively evaluated to date. Thus, the purpose of this paper is to assess Noah-simulated soil temperature for different soil depths and time scales. The authors used long-term (1979-2001) observed monthly mean soil temperatures from 137 cooperative stations over the United States to evaluate simulated soil temperature for three soil layers $(0-10,10-40$, and 40-100 cm) for annual and monthly time scales. Short-term (1997-99) observed soil temperatures from 72 Oklahoma Mesonet stations were used to validate simulated soil temperatures for three soil layers and for daily and hourly time scales. The results showed that the Noah land surface model generally matches observed soil temperature well for different soil layers and time scales. At greater depths, the simulation skill (anomaly correlation) decreased for all time scales. The monthly mean diurnal cycle difference between simulated and observed soil temperature revealed large midnight biases in the cold season that are due to small downward longwave radiation and issues related to model parameters.
\end{abstract}

\section{Introduction}

Climatic modeling studies have demonstrated that soil moisture plays an important role in land-atmosphere interactions at different time scales (Avissiar and Pielke 1989; Betts et al. 1996; Dirmeyer et al. 2000; Koster and Suarez 2003; Koster et al. 2004). It provides a key link between the atmosphere and land surface moisture and energy partitioning through soil evaporation and transpiration processes (Robock et al. 2000). However, the role of soil temperature and its influence on weather and

Corresponding author address: Youlong Xia, Environmental Modeling Center, NOAA National Centers for Environmental Prediction, Camp Springs, MD 22046.

E-mail: youlong.xia@noaa.gov climate, especially its effect on short-range weather processes, have been underestimated in the past (Godfrey and Stensrud 2008). Soil temperature directly affects the surface radiation budget through upward longwave radiation and ground heat flux as both depend on soil temperature. In addition, ground heat flux also affects sensible heat flux, boundary layer dynamics, turbulence, and air temperature. Recent studies from the National Centers for Environmental Prediction (NCEP) operational Eta model (Godfrey and Stensrud 2008) and Weather Research and Forecasting Model (Fan 2009) show that soil temperature has significant effects on short-term model forecasts of near-surface variables such as precipitation and lower-atmospheric circulation fields. A modeling study from Xue et al. (2001) demonstrated that subsurface soil temperature over the 


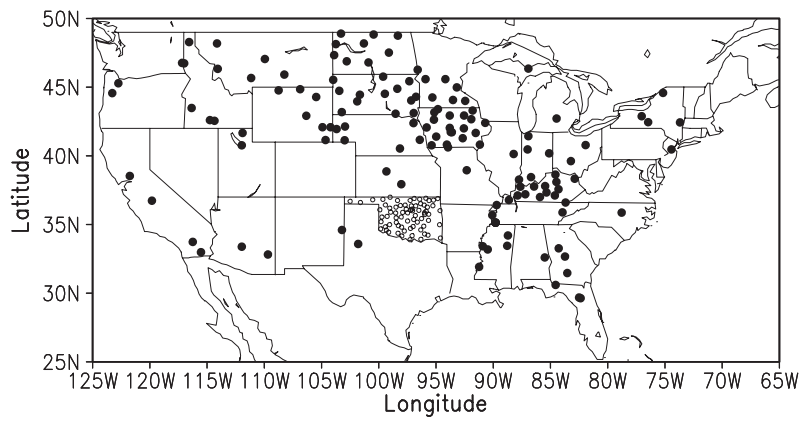

FIG. 1. Locations of the 137 U.S. cooperative stations (closed circles) and 72 Oklahoma Mesonet stations (open circles).

western United States in late spring has an impact on summer precipitation. Mahanama et al. (2008) used the National Aeronautics and Space Administration (NASA) atmospheric general circulation model to investigate the impact of subsurface soil temperature variability on surface air temperature variability. The results show that allowing an interactive subsurface soil temperature significantly increases surface air temperature variability in most regions, which provides some skill to subseasonal and seasonal forecasts. Hu and Feng (2004) used observed soil temperature over the continental United States (CONUS) to find evidence of a connection between late spring soil temperature and summer precipitation. On the other hand, shallow soil temperature anomalies may affect short-term weather processes because soil heat anomalies with daily or weekly time scales are released to the overlying atmosphere before they transfer to deep soil layers. Deep soil temperature anomalies affect regional climate processes through gradual and slow release the extra heat to shallow soil layers (Hillel 1980). Therefore, soil temperature, in addition to soil moisture, is gaining consideration as another important initial condition for both weather and climate models.
Soil temperature anomalies at various depths also directly influence yield of agricultural crops such as corn, beans, and oats. Soil temperature can impact an array of ecological processes, in particular vegetation growth (McMichael and Burke 1998), soil biological, and chemical activity (Kirschbaum 1995). For agriculture, soil temperature affects plant growth directly including nutrient uptake as well as indirectly in soil water and gas flow, soil structure, and nutrient availability (Tindall et al. 1990); for instance, a warm near-surface soil during spring speeds up crop growth while cooler soil temperatures do the opposite, making soil temperature a useful predictor for crop growth and yield. The combination of soil temperature and soil moisture strongly affects soil $\mathrm{CO}_{2}$ efflux. Therefore, high-quality soil temperature observations are needed for both weather and climate models as well as for plant models as initial conditions and forcing data.

Despite the need for these data, there are currently very few high-quality, in situ soil temperature observations available. Thus, model-based soil temperature products often serve as alternatives for observations. Simulated soil temperature products can be derived from coupled climate models or offline land surface models. Zhu and Liang (2005) examined the capability of the fifth-generation Pennsylvania State University-National Center for Atmospheric Research Mesoscale Model (MM5)-based regional climate model in simulating the U.S. soil temperature annual cycle and interannual cycle. Comparisons between simulated and observed soil temperature at a 10-cm depth over the central United States for the period during 1982 and 2001 showed large cold biases in summer and fall. Robock et al. (2003) evaluated the North American Land Data Assimilation phase 1 (NLDAS-1) soil temperature products generated from two land surface models [Noah, Ek et al. 2003; Variable Infiltration Capacity (VIC), Liang

TABLE 1. Locations and measurement system of 14 ARM/CART stations in Oklahoma.

\begin{tabular}{|c|c|c|c|c|c|}
\hline Station name & Lat $\left(^{\circ}\right)$ & Lon $\left(^{\circ}\right)$ & Vegetation cover & SIRS & EBBR \\
\hline Byron & 36.881 & -98.285 & Alfalfa & Yes & No \\
\hline Pawhuska & 36.605 & -97.485 & Native prairie & Yes & Yes \\
\hline Lamont & 36.431 & -98.284 & Pasture and wheat & Yes & Yes \\
\hline Ringwood & 36.061 & -99.134 & Pasture & Yes & Yes \\
\hline Vici & 35.687 & -95.856 & Wheat & Yes & No \\
\hline Morris & 35.564 & -96.988 & Pasture & Yes & Yes \\
\hline El Reno & 35.615 & -96.065 & Pasture & Yes & Yes \\
\hline Meeker & 35.354 & -98.977 & Pasture & Yes & Yes \\
\hline Okmulgee & 34.883 & -98.205 & Forest & Yes & No \\
\hline Cordell & 34.957 & -98.076 & Rangeland & Yes & Yes \\
\hline Fort Cobb & 36.841 & -96.427 & Pasture & No & No \\
\hline Cyri & 35.557 & -98.017 & Wheat & Yes & No \\
\hline Seminole & 35.153 & -98.461 & Pasture & Yes & Yes \\
\hline Cement & 35.245 & -96.736 & Pasture & No & Yes \\
\hline
\end{tabular}



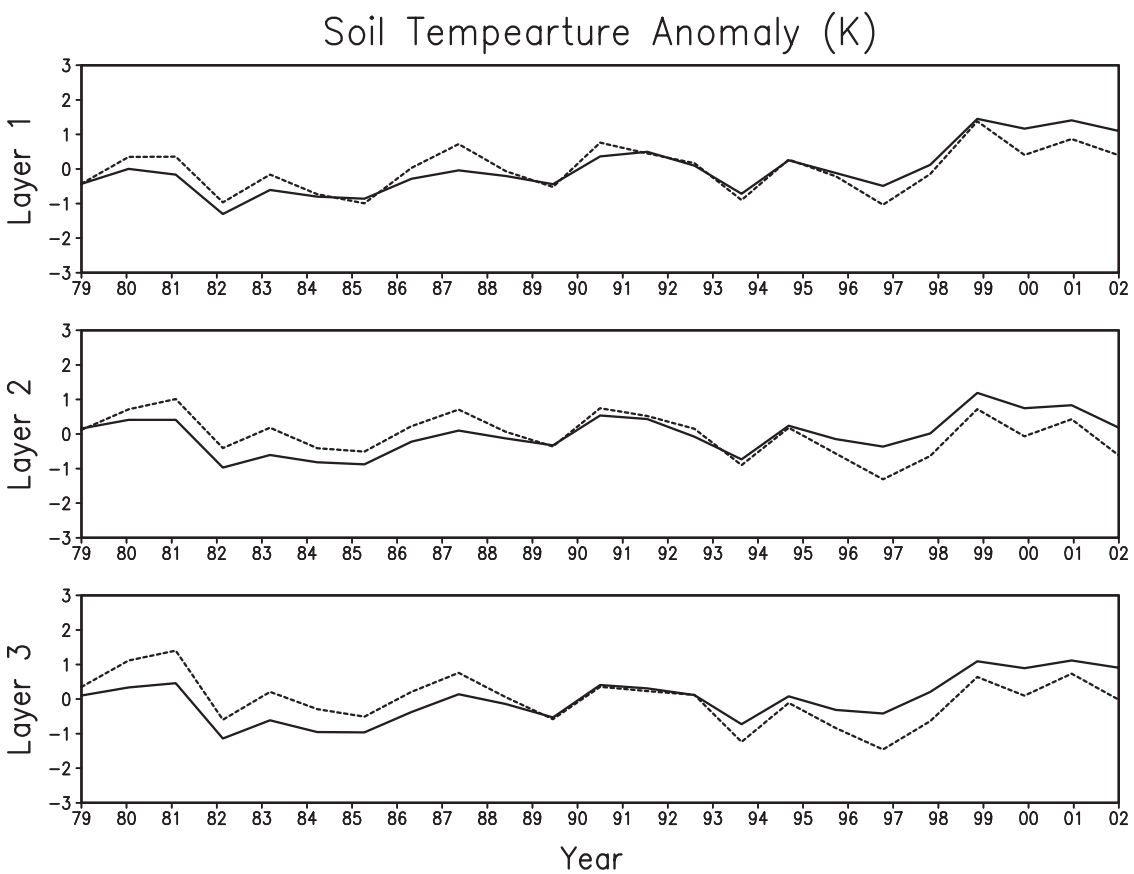

FIG. 2. Interannual variability of observed (solid line) and simulated (dotted line) annual mean soil temperature anomaly averaged over 137 stations of the CONUS at (top to bottom) the first layer soil layer: 0-10 cm, the second soil layer: 10-40 cm, and the third soil layer: 40$100 \mathrm{~cm}$ during the period from 1979 to 2001.

et al. 1994] derived by given atmospheric forcing. They compared simulated daily soil temperature with observations averaged at 72 Oklahoma Mesonet stations for a period from 1 January 1998 to 31 December 1999. The results showed that both land surface models simulated the near-surface soil temperature (5-cm depth) well (bias is smaller than $5 \mathrm{~K})$. At greater depth (25-cm depth), the models were still fairly close to observations, with a maximum difference less than $5 \mathrm{~K}$.

Recently, NLDAS-1 was extended from a 3-yr simulation (1 October 1996-30 September 1999) to a 30-yr simulation [NLDAS phase 2 (NLDAS-2), 2 January 1979-31 December 2008] using four upgraded land surface models [Noah, Mosaic, the Sacramento soil moisture accounting model (SAC), and VIC] and improved atmospheric forcing data (Xia et al. 2012a), derived from the North American Regional Reanalysis (NARR; Mesinger et al. 2006) and the NCEP Climate Prediction Center (CPC) gauge-only precipitation. NARR downward shortwave radiation was corrected by using a ratiobased (Berg et al. 2003) bias correction technique and the University of Maryland's Surface Radiation Budget dataset (Pinker et al. 2003). The CPC gauge-only precipitation was corrected using a topographic adjustment based on the widely applied Parameter-Elevation Regressions on Independent Slopes Model (PRISM) climatology
(Daly et al. 1994). Among the four land surface models, SAC does not include soil temperature calculations, and Mosaic has only one soil temperature for its forcerestore calculations; that is, the soil temperature is not tied to a particular layer. The VIC soil temperature was not available for NLDAS-2 because it had no output. Therefore, only Noah produced a 30-yr hourly soil temperature with a $1 / 8^{\circ}$ spatial resolution at 5-, 25-, 70-, and 150-cm depth, which was available for this study. To date, the model-simulated soil temperature products in the NLDAS-2 have not been rigorously evaluated and validated against in situ measured soil temperature because of the lack of long-term soil temperature over CONUS. $\mathrm{Hu}$ and Feng (2004) generated a long-term (from January 1967 to March 2002) monthly observed soil temperature dataset over the CONUS using a set of quality control methodologies (Hu and Feng 2002, 2003). There are only about 60 stations at all five depths (i.e., 5, 10, 20, 50 , and $100 \mathrm{~cm}$ ) except for the $10-\mathrm{cm}$ depth where there are over 292 stations. This in situ monthly soil temperature observation dataset provides an opportunity to evaluate the seasonality and interannual variability of long-term NLDAS-2 soil temperature products. In addition, this dataset will be applied to assess Noah simulation skill, simulation errors, and memory characteristics of simulated soil temperature. Meanwhile, we use the 

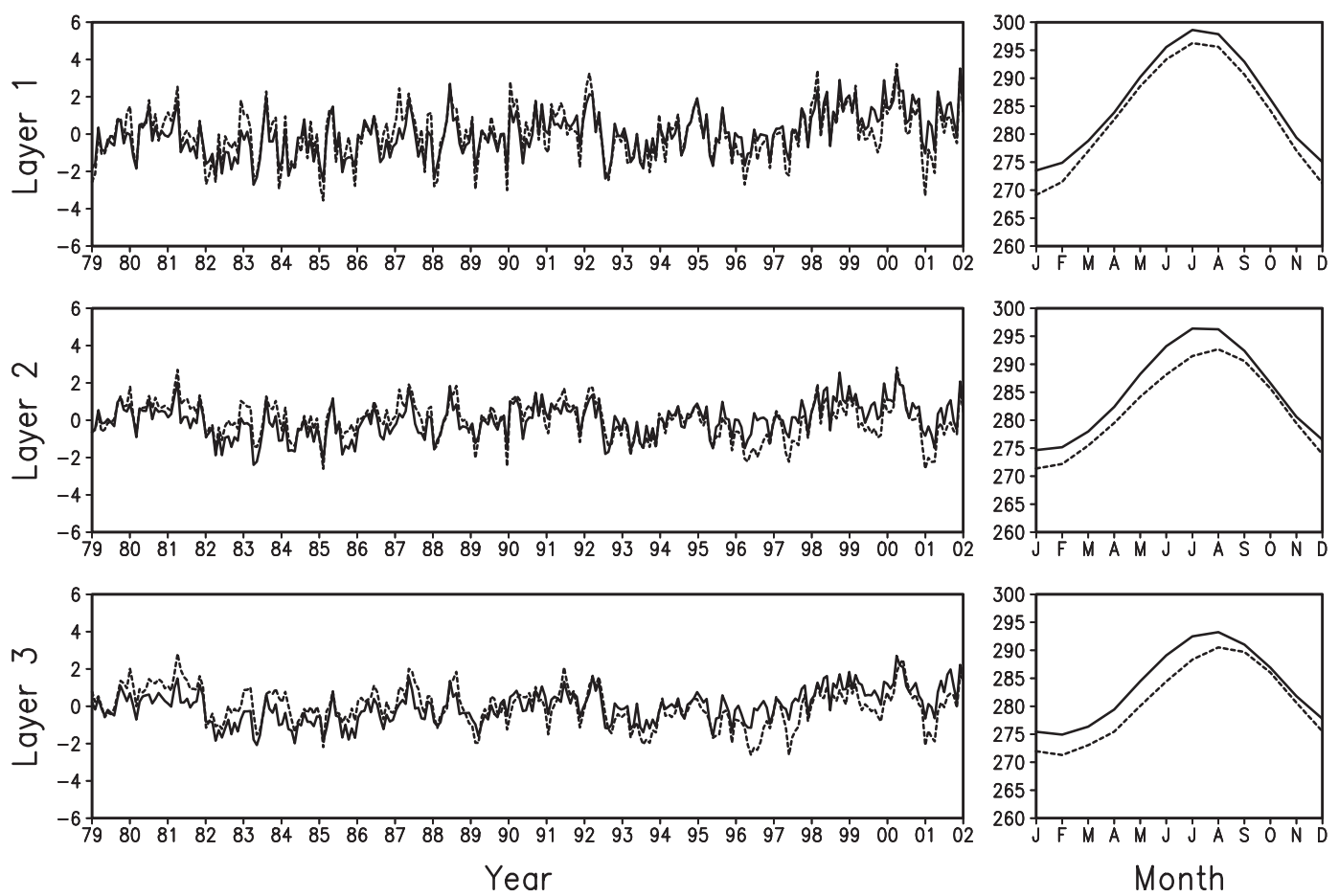

FIG. 3. Monthly variation of the observed (solid) and simulated (dotted line) (left) monthly mean soil temperature anomaly and (right) monthly mean soil temperature climatology in the (top to bottom) three soil layers. The monthly mean soil temperature was averaged from 137 stations over the United States. The time period covers from January 1979 to January 2002.

3-yr (from 1 January 1997 to 31 December 1999) in situ soil temperature measurements at 72 Oklahoma Mesonet stations to evaluate simulated daily and hourly soil temperatures from the NLDAS-2.

The validation data details used in this study are described in the next section. Results from the validation of annual, monthly, daily, and hourly soil temperature are presented and discussed in section 3. Section 4 contains a summary of the study and some remarks on the most relevant findings and future work.

\section{Validation data description}

This study uses datasets of two in situ soil temperature measurements. The first is of long-term monthly soil temperature that was derived from daily soil temperature observations at 137 sites over the CONUS (Fig. 1). A monthly mean value was calculated for a given month and depth if 1) the daily data had fewer than 10 missing values and the missing values were scattered in the given month, and 2) the daily series had less than 5 consecutive missing values. Otherwise, the monthly mean value was considered as missing (Hu and Feng 2004). NLDAS-2 soil temperature extends from January 1979 to December 2008, while in situ monthly soil temperature measurements cover from January 1967 to March 2002. Thus, we selected the period of overlap from January 1979 to January 2002 as the temporal domain for this study. The number of stations varied depending on depth and month of interest because of missing records. The 292 stations used in Hu and Feng (2003) were reduced to 137 stations by removing stations with no measurements for all 5 measurement layers and the stations with only records at a $10-\mathrm{cm}$ depth. We used a simple linear interpolation algorithm to interpolate soil temperature from measurement layers to facilitate comparison with Noah model layers of 25 and $70 \mathrm{~cm}$. The accuracy of measured soil temperature was within $\pm 1.0 \mathrm{~K}$ for all soil layers ( $\mathrm{Hu}$ and Feng 2002).

The second dataset is the Oklahoma Mesonet monitoring network (Brock et al. 1995) that includes 115 automated stations covering every county of Oklahoma. Soil temperature was measured at more than 72 sites (Fig. 1) at depths of 5, 25, 60, and $75 \mathrm{~cm}$ to provide continuous observations of soil temperature change. The accuracy of measured temperature was within $\pm 0.5 \mathrm{~K}$ (Robock et al. 2003).

The Noah model has four soil layers: 0-10, 10-40, 40-100, and 100-200 cm. The soil temperature was simulated at the midpoint of each soil layer (i.e., 5, 25, 70, and 
(a) COR

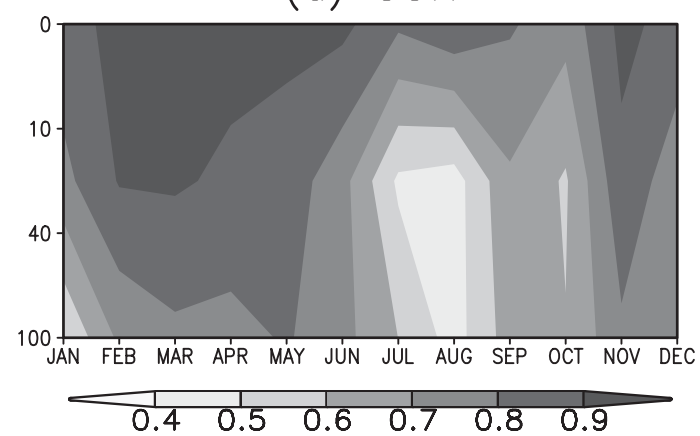

(c) MAE (K)

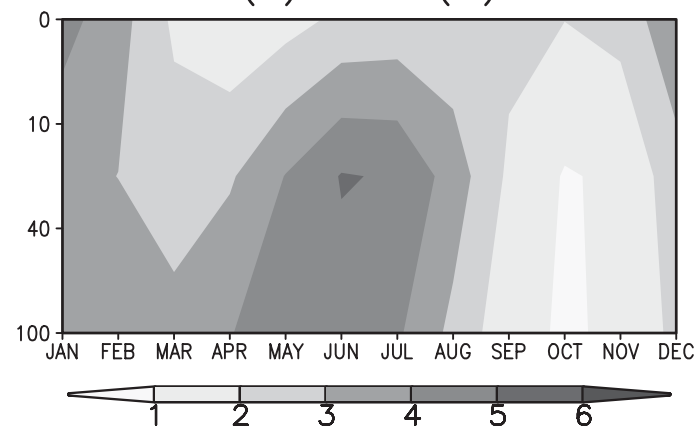

(b) RMSE (K)

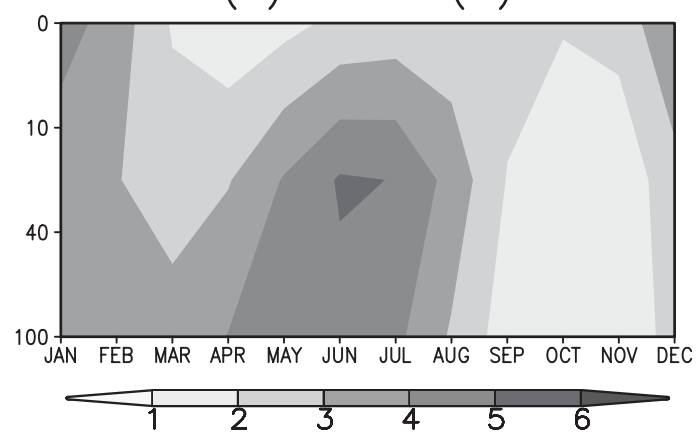

(d) $M E(K)$

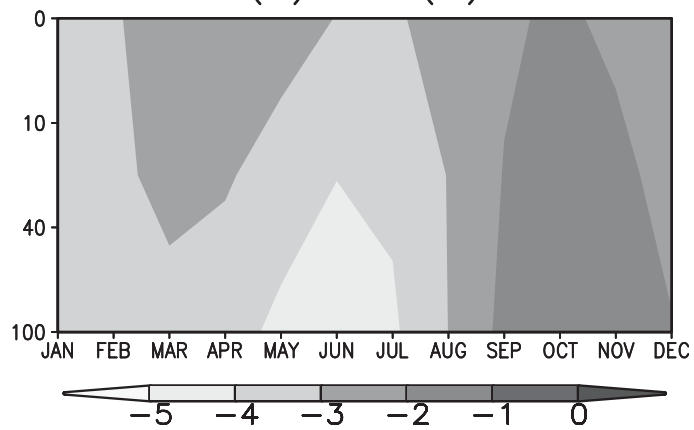

FIG. 4. Variation of four statistical metrics with month and depth for (a) monthly mean soil temperature anomaly COR, (b) RMSE between simulated and observed monthly soil temperature, (c) MAE between simulated and observed soil temperature, and (d) ME between simulated and observed soil temperature.

$150 \mathrm{~cm}$ ). The spatial resolution of simulated temperature is $1 / 8^{\circ}$ and its temporal resolution was hourly.

Observed downward shortwave radiation, downward longwave radiation, upward longwave radiation, and ground heat fluxes from 14 Atmospheric Radiation Measurement Program/Cloud and Radiation Test Bed (ARM/CART; Robock et al. 2003) stations in Oklahoma (Table 1) were used to compare model-simulated results. The purpose was to diagnose whether model forcing error was a possible reason for Noah-simulated soil temperature error. Downward and upward shortwave and longwave radiation were measured by the Solar and Infrared Radiation Stations (SIRS) instruments and surface energy fluxes were measured by in situ sensors-an energy balance Bowen ratio (EBRR) system (Robock et al. 2003). The corresponding downward shortwave and longwave radiation were obtained from NLDAS forcing, which were derived from NARR reanalysis products (Xia et al. 2012a), and upward longwave radiation and ground flux were obtained from Noah model output. Since radiative skin temperature was more often used to explain soil temperature biases, both observed and simulated upward longwave radiation were converted to radiative skin temperature with the assumption that surface emissivity was 1.0 for a consistency.

\section{Validation of simulated soil temperature}

Given the lack of coincident soil temperature measurements, a direct comparison between simulated soil temperature and observations at each individual station was not possible because this kind of comparison suffers from scale incompatibility. Since soil temperature spatial variation related to soil characteristics was highly heterogeneous (Vinnikov et al. 1996; Crow and Wood 1999; Entin et al. 2000), site observations could not represent simulated soil temperatures at a $1 / 8^{\circ}$ grid box. Therefore, there are inherent inconsistencies in making a direct comparison between simulations and observations using a gridbox value and a point value. A simple spatial average could reduce this uncertainty and has been used in many similar validations (Robock et al. 1998, 2003; Entin et al. 1999; Zhu and Liang 2005; Fan et al. 2006). Spatial and temporal averaging reduces the spatial and temporal noise and therefore provided a more meaningful comparison.

To make a consistent comparison between model output and observations, the spatial averaging was done only when and where both modeled and observed values were present simultaneously. Since the number of stations used for averaging was different for each layer 

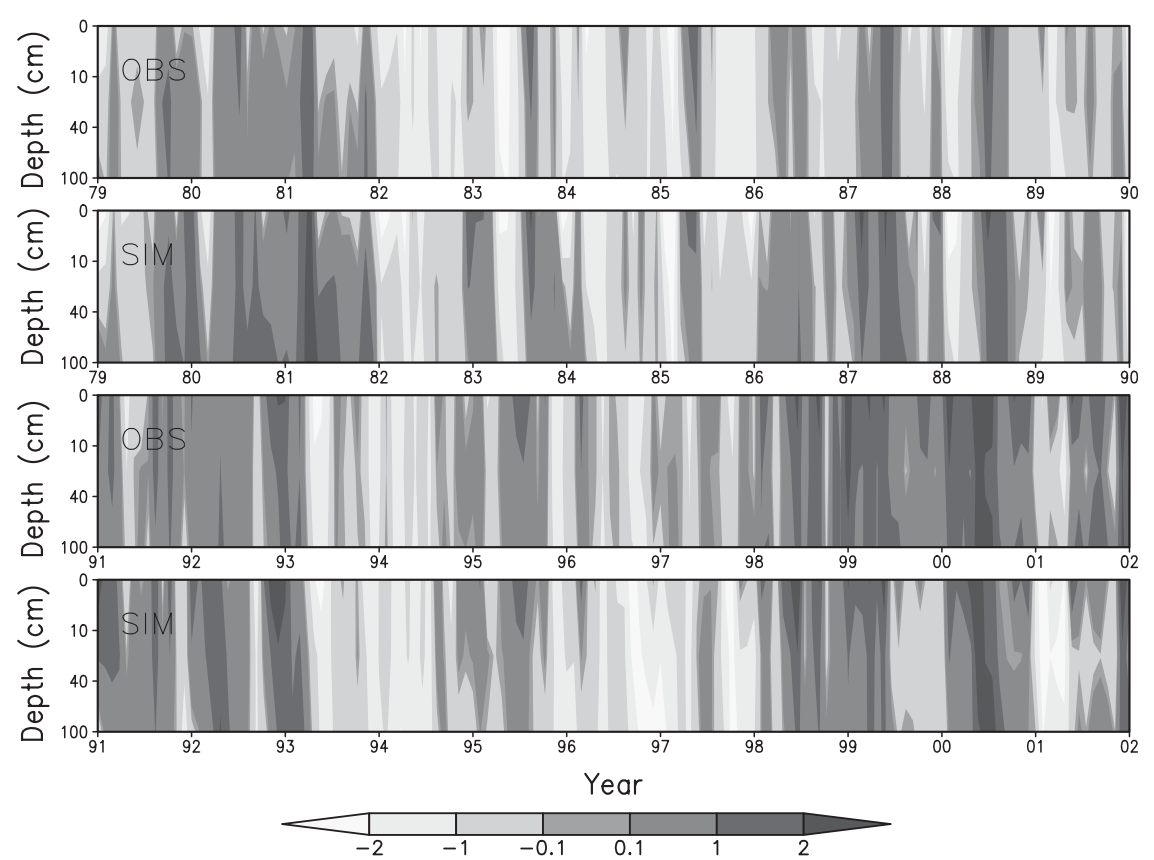

FIG. 5. Observed and simulated vertical distribution in top $100 \mathrm{~cm}$ of monthly mean soil temperature anomalies (K) averaged over the United States, as time series from January 1979 to January 2002.

and month because of missing data, we average all available observations to maximize the sample size as used in Robock et al. (2003). In the following sections, we validated modeled soil temperature at annual, monthly, daily, and hourly time scales, respectively.

\section{a. Validation of annual mean soil temperature}

Figure 2 compares the observed and Noah-simulated 1979-2001 variations of annual mean soil temperature anomaly at 5,25 , and $70 \mathrm{~cm}$. The interannual variations of soil temperature anomalies were well captured by the Noah land surface model (LSM), with an overall mean absolute error of $0.3 \mathrm{~K}$ at $10 \mathrm{~cm}, 0.42 \mathrm{~K}$ at $25 \mathrm{~cm}$, and $0.51 \mathrm{~K}$ at $70 \mathrm{~cm}$. Observed annual mean soil temperature was $285.6,285.0$, and $283.6 \mathrm{~K}$ and simulated annual mean soil temperature was $283.1,282.1$, and $280.6 \mathrm{~K}$ for 0-10-, 10-40-, and 40-100-cm soil layers, respectively. The Noah model captured all cold and warm events for three soil layers. There was a positive (negative) bias before (after) 1993. The reason for the systematic bias may be inconsistency in the timing of soil temperature observations resulting from using three different data sources (Hu and Feng 2003) that cover different periods, as the same issue was noted by Zhu and Liang (2005). The inconsistency is largely attributed to a change in the instrument measuring soil temperature that occurred in 1993 (X. Liang 2011, personal communication). The correlation coefficients between mean annual simulated and observed soil anomaly were 0.85 at $10 \mathrm{~cm}, 0.63$ at $25 \mathrm{~cm}$, and 0.60 at $70 \mathrm{~cm}$, respectively. All anomaly correlations were statistically significant at the $95 \%$ confidence level and the Noah LSM had larger simulation skill in the top soil layer versus the bottom layer.

\section{b. Validation of monthly mean soil temperature}

The seasonal cycle and monthly variability of the observed and simulated averaged soil temperature in three soil layers $(0-10,10-40$, and $40-100 \mathrm{~cm})$ for the period from January 1979 to December 2001 is shown in Fig. 3. The time evolution of the simulated anomalies of all three soil layers followed the observations quite well, and most warm and cold events were captured very well. However, exceptions can be seen, such as the 1996 and 1997 cases where the simulated soil temperature anomaly was too cold when compared with the observed soil temperature anomaly for lower two layers. The phase of the seasonal cycle of three soil layers was also well simulated, but the simulated mean was colder than observations by $2-5 \mathrm{~K}$, subject to different soil layers and months. This discrepancy was associated with potentially unrepresentative model parameters that were chosen for Noah model (discussed in section 4). The anomaly correlation between the observed and simulated soil temperature were $0.87,0.77$, and 0.69 for $0-10,10-40$, and $40-100 \mathrm{~cm}$, respectively, showing decreasing trend with increasing depth. Figure 4 shows the seasonal variation of monthly 

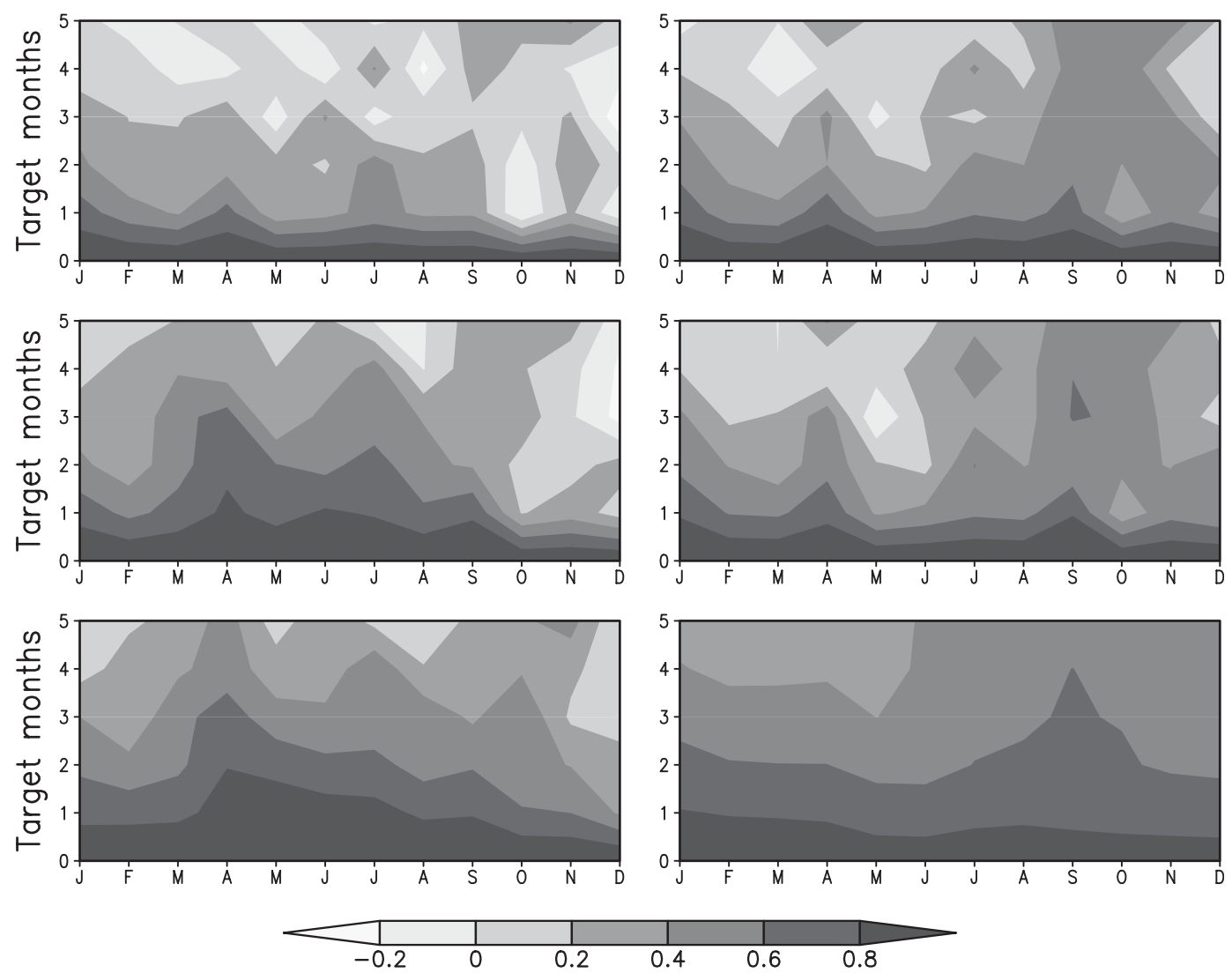

FIG. 6. Variation of (left) observed and (right) simulated soil temperature persistence (month-to-month autocorrelation) with month for (top to bottom) three soil layers $(0-10,10-40$, and 40-100 cm) for 1979-2002 over the United States. The initial month is along the $x$ axis, and the lead to the target month (lag months) is along the $y$ axis.

anomaly correlation (COR) and errors for different soil depths. As soil depth increases, the anomaly correlation decreases (Fig. 4a). The largest anomaly correlation occurred during November and May in the top 10-cm soil layer, and the smallest anomaly correlation occurred during July and August in the bottom two soil layers (10$40,40-100 \mathrm{~cm}$ ). Smaller anomaly correlations in summer and larger anomaly correlations in winter were is in agreement with the results of Zhu and Liang (2005). Root-mean-square error (RMSE) and mean absolute error (MAE) between observed and simulated soil temperature showed a similar spatial-temporal pattern (Figs. $4 b, c)$. Large errors exist in the bottom two layers for the period from April to July, and small errors exist in the bottom two layers for the period during September and November. For all soil layers and months, Noah LSM had significant negative biases [mean error (ME)] when compared with the observations. Small biases exist in all soil layers during the period from September to December and in the top two layers during February and May, and large biases exist in the bottom two layers during May and July (Fig. 4d). These soil temperature biases may have been caused by deficiencies in Noah model representations of physical processes in atmospheric surface and soil layers.

The monthly time evolution of the observed and simulated soil temperature anomalies averaged over the CONUS as a function of depth are shown in Fig. 5. In general, the Noah LSM realistically captured most large cold and warm events for the top $100 \mathrm{~cm}$ of the soil column. However, the Noah LSM tended to overestimate warm events and underestimate cold events before 1993. This was consistent with Fig. 2 in which there was a positive anomaly before 1993 and a negative anomaly after 1993 for all three soil layers given the observed soil temperature inconsistency.

The autocorrelation coefficient of observed and simulated soil temperature anomalies as a function of the starting month and target month (lag month) for all three soil layers (Fig. 6) shows that soil temperature persistence was seasonally dependent. Overall, the general characteristics of observed and simulated soil temperature persistence were similar. Soil temperature anomalies persisted approximately $1-1.5$ months in the first soil layer, 1-3 months in the second soil layer, and 1-4 months in the 
third soil layer, subject to different seasons. Observed soil temperature displayed stronger persistence than simulated soil temperature in the bottom two soil layers probably because of inadequate heat storage in the Noah model. As soil depth increased, persistence of both observed and simulated soil temperature became stronger. April soil temperature exhibited a strong persistence for all soil layers. In the first soil layer, the model results agreed well with observations in both phase and amplitude for all months except for the period of SeptemberOctober. During that period, the Noah-simulated soil temperature displayed stronger persistence. As soil depth increased, the difference between simulations and observations became larger. In the second and third soil layer, Noah-simulated soil temperature exhibited stronger persistence than observations in January, September, October, and November, while it showed weaker persistence in spring and summer. The reason for this inconsistency is still unknown. More sensitivity tests are needed to address this issue in the future.

\section{c. Validation of daily mean soil temperature}

We used monthly mean soil temperature observation from the 137 stations of the CONUS to evaluate Noah LSM simulations for annual and month time scales. For daily and hourly time scales, we used 72 Oklahoma Mesonet stations to assess Noah LSM simulations. Figure 7 shows the 3-yr (1997-99) averaged soil temperature for the three soil layers from the Noah LSM. When compared with observations, Noah LSM simulated the nearsurface soil temperature quite well. Even for the second and third soil layers, Noah LSM simulations were quite close to the observations, with a maximum mean difference less than $3 \mathrm{~K}$. This was similar to the results of Robock et al. (2003) where Noah had maximum mean difference $5 \mathrm{~K}$. This slight improvement was due to the upgrade of Noah model and improvement of forcing data (Xia et al. 2012a,b). Noah LSM soil temperature followed observations more closely in the fall than in spring, which was also the case in Robock et al. (2003). Since they had less than 2 years of data, they could not confirm whether this is a systematic bias. However, when we used long-term (1979-2001) monthly mean soil temperature observations over the CONUS (Fig. 3) and short-term (1997-2000) daily mean soil temperature observations over Oklahoma, the similar systematic bias can be seen. The reason leading to this systematic bias remains unclear, and it is left for future study. Figure 8 shows the variation of soil temperature anomaly correlation and ME between simulated and observed daily soil temperature for three soil layers. The results show that there was limited anomaly correlation during two periods-July to August and April to May—and large
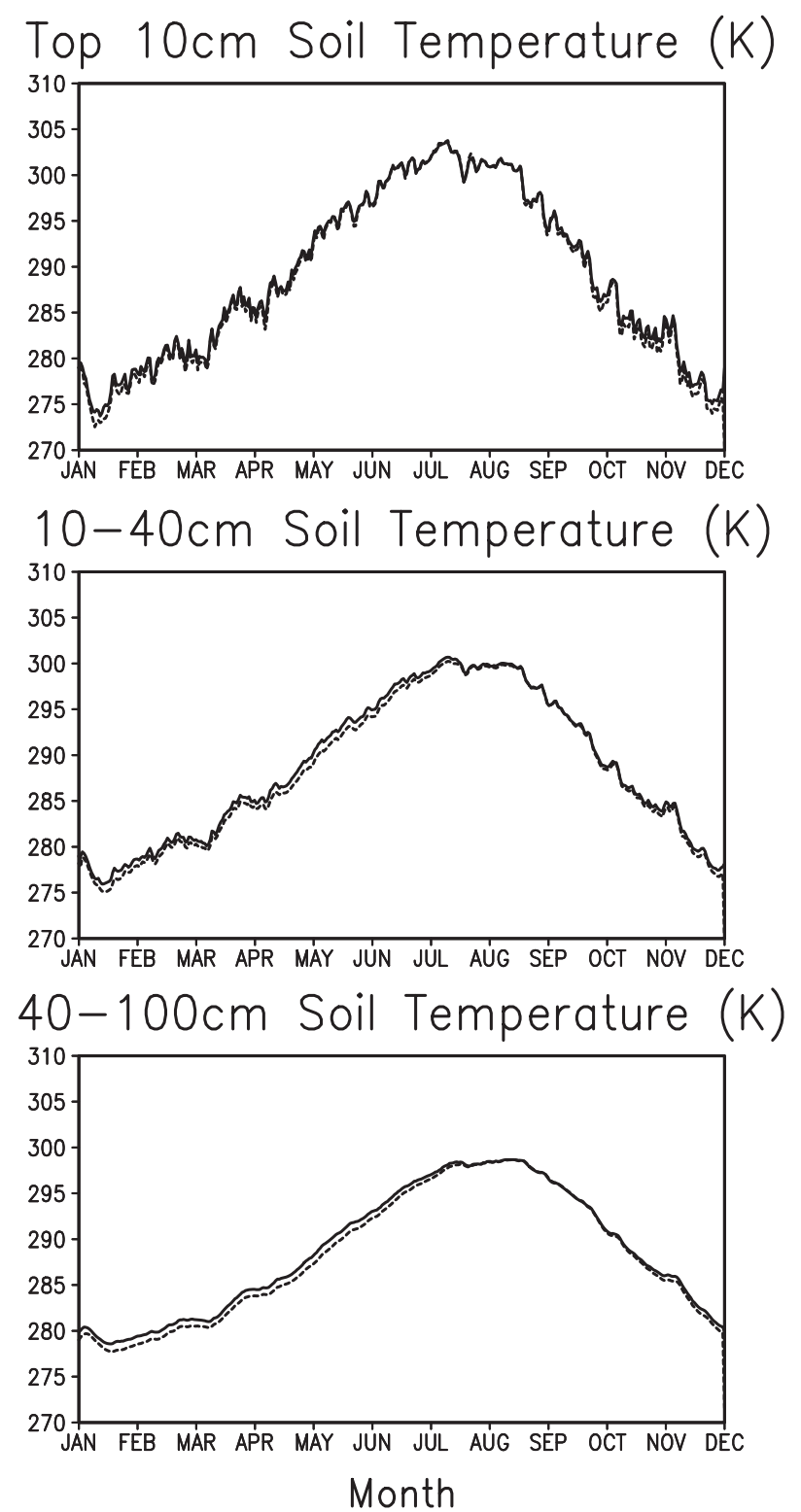

FIG. 7. Time series of 3-yr (1997-99) mean soil temperature for (top to bottom) three soil layers $(0-10,10-40$, and $40-100 \mathrm{~cm}$ ) compared with observations at three depths $(5,25,70 \mathrm{~cm})$. Solid line is observations and dotted line is simulations. The soil temperature was spatially averaged from 72 Oklahoma Mesonet stations.

correlation in the other months (Fig. 8a). The ME analysis showed that Noah had larger errors in winter and smaller errors in summer and early fall for the first layer (Fig. 8b), while it had larger errors in spring and smaller errors in late summer and fall for bottom two layers. Figure 9 shows observed and simulated soil temperature profile for the period during 1 July and 29 October of two years (1997 and 1998). In general, observed and simulated spatiotemporal patterns are similar and overall performance of the Noah LSM was quite good. 


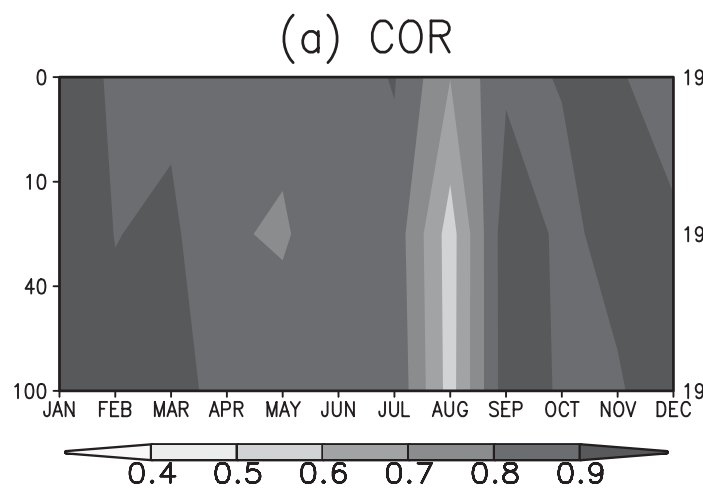

(c) 2nd layer ME (K)

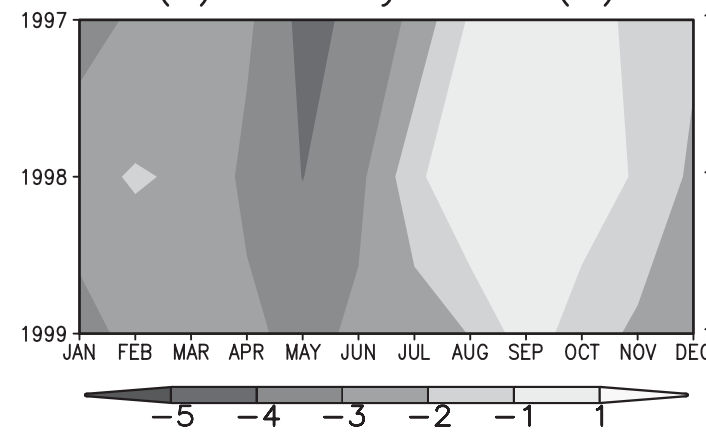

FIG. 8. Statistical analysis of daily soil temperature for three soil layers $(0-10,10-40$, and $40-100 \mathrm{~cm})$. (a) Variation of daily anomaly correlation with month and depth, (b) variation of ME (bias) between simulated and observed daily soil temperature with month and year for the first layer, (c) variation of ME with month and year for the second layer, and (d) variation of ME with month and year for the third layer.
Meanwhile, comparisons of simulated and observed soil temperatures revealed that the Noah LSM was able to catch the response of soil temperature to cold and warm weather processes and could simulate downward propagation of soil temperature change, although simulated soil temperature was too cold in fall.

\section{d. Validation of hourly soil temperature}

Figure 10 shows a comparison between simulated soil temperature by the Noah LSM and the observations for three soil layers. The diagram shows the monthly mean diurnal cycles of soil temperature averaged over 72 Oklahoma Mesonet stations and the differences between the simulated soil temperature and the observations. The observed soil temperature showed a clear diurnal cycle in the top soil layer, that is, there was high soil temperature on midday and low soil temperature in the midnight. As soil depth increased, the amplitude of monthly mean diurnal cycle decreased. The Noah LSM did a good job in simulating hourly soil temperature in summer for all three soil layers with an error less than $2 \mathrm{~K}$. It also simulated daytime soil temperature very well for all season and soil layers. However, Noah LSM underestimated midnight soil temperature systematically throughout the 36 months by up to $5 \mathrm{~K}$ in the $0-10$-cm soil layer for cold season (October-April). As soil depth increased, the differences between simulated and observed soil midnight temperature decreased from $5 \mathrm{~K}$ in the first soil layer to $3 \mathrm{~K}$ in the third soil layer.

The soil temperature dataset from the Oklahoma Mesonet used for daily and hourly validation was a nonstandard soil temperature dataset. This was a special dataset created from observations collected by the soil moisture sensors installed at Oklahoma Mesonet sites, although it was used in NLDAS-1 validation (Robock et al. 2003). The Oklahoma Mesonet now has a number of soil temperature sensors installed at 5, 10, and $30 \mathrm{~cm}$ under native vegetation (McPherson et al. 2007). These observations have been collected at over 100 stations since 1994. Further, these soil temperature observations receive the full suite of quality assurance and quality control that the mesonet provides (McPherson et al. 2007). However, a lot of missing values were noted before 1999, and thus, we selected 12-yr (1999-2010) hourly soil temperature at 3 soil layers $(5,10,30 \mathrm{~cm})$ over 114 127 stations (subject to different years). The dataset is 


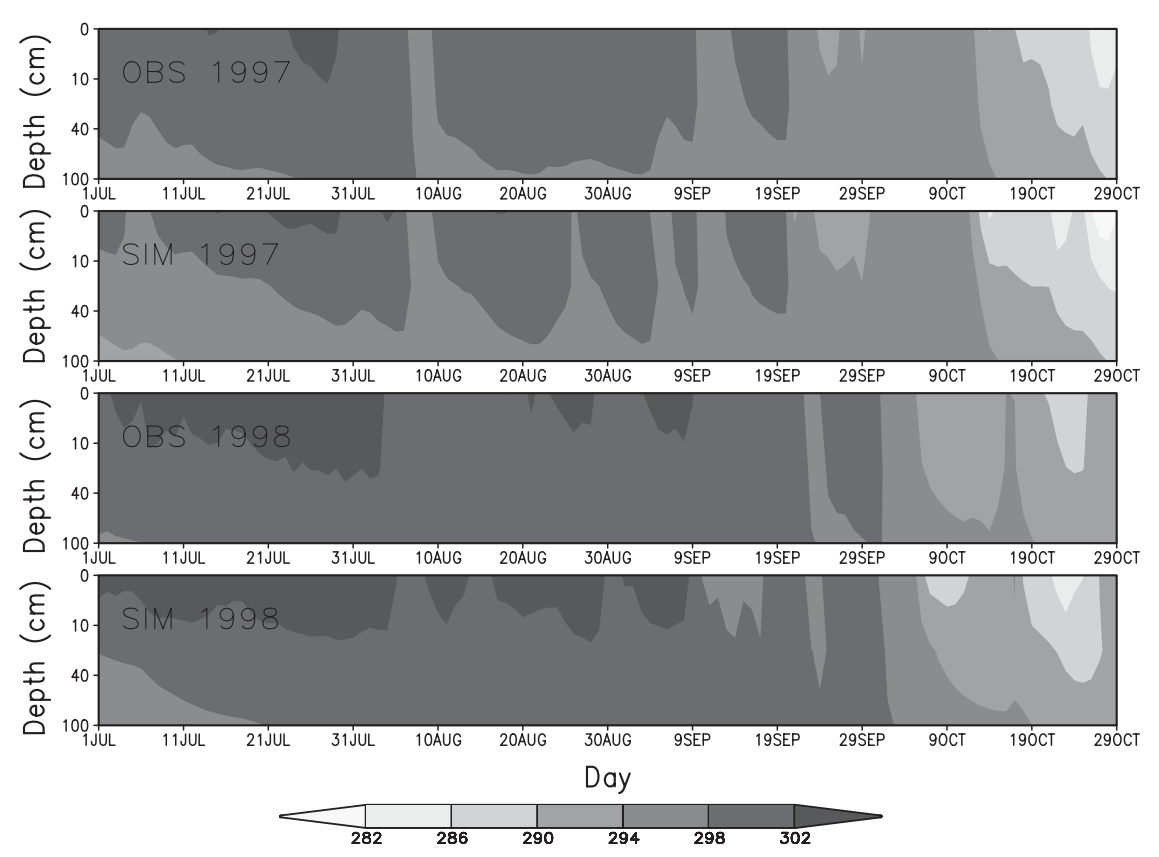

FIG. 9. Observed and simulated daily soil temperature profile for 1 Jul-29 Oct 1997 and 1 Jul-29 Oct 1998.

detailed in the appendix to facilitate further evaluation of Noah simulations. We interpolated between measured soil temperatures onto 5- and $25-\mathrm{cm}$ depths to match Noah's two model soil layers (middle layers are 5 and $25 \mathrm{~cm}$, respectively). We repeated the hourly validation process as was done for nonstandard soil temperature. Figure 11 shows the 12-yr averaged diurnal cycle differences between Noah simulations and observations at 5 and $25 \mathrm{~cm}$. Noah underestimated soil temperature during nighttime in winter and overestimated soil temperature during daytime in summer for the top soil layer. Noah underestimated soil temperature at the $25-\mathrm{cm}$ soil layer for all seasons except for summer. Both temporal pattern and quantity were in good agreement with the validation using nonstandard soil temperature observations. This further demonstrated the robustness of our validation results in this study.

\section{Summary and discussion}

This investigation compared soil temperature simulations from the Noah LSM at several soil depths with observations from U.S. cooperative stations over the CONUS for annual and monthly time scales and at the Oklahoma Mesonet for daily and hourly time scales. The model captured the broad features of observed soil temperature variations for all three soil layers, in particular the daily, monthly, and annual anomalies associated with cold and warm events. Noah skills in simulating soil temperatures varied with season, soil depth, and time scale. Noah had lower simulation skill (anomaly correlation) in summer and higher simulation skill in winter and fall for both monthly and daily time scales. As soil depths increased, simulation skills decreased. There were large negative biases in simulated soil temperature for all time scales and soil layers. The negative bias was $2.5-$ $3.0 \mathrm{~K}$ for annual mean soil temperature and less than $5 \mathrm{~K}$ for daily and monthly mean soil temperature. These biases varied by season and soil layer. For all soil layers there was a smaller bias in fall and larger bias in summer for monthly mean soil temperature. For daily mean soil temperature in the top shallow layer, there were smaller errors in summer and early fall and larger errors in late fall and early winter. In the bottom two layers, small errors arose in late summer and fall and large errors arose in spring. In contrast to negative bias for monthly mean soil temperature, daily soil temperature analysis showed that small positive biases existed over the Oklahoma Mesonet in summer and fall for all soil layers. For hourly soil temperature, Noah LSM had large negative biases during nighttime from late fall to early spring.

The differences between Noah LSM and the observations were attributed to soil temperature measurement error, interpolation error (i.e., measured soil temperature was interpolated to model soil layers), model soil parameters (i.e., soil texture may have been different from that used in the Noah LSM), atmospheric forcing data errors, and model structural errors. 

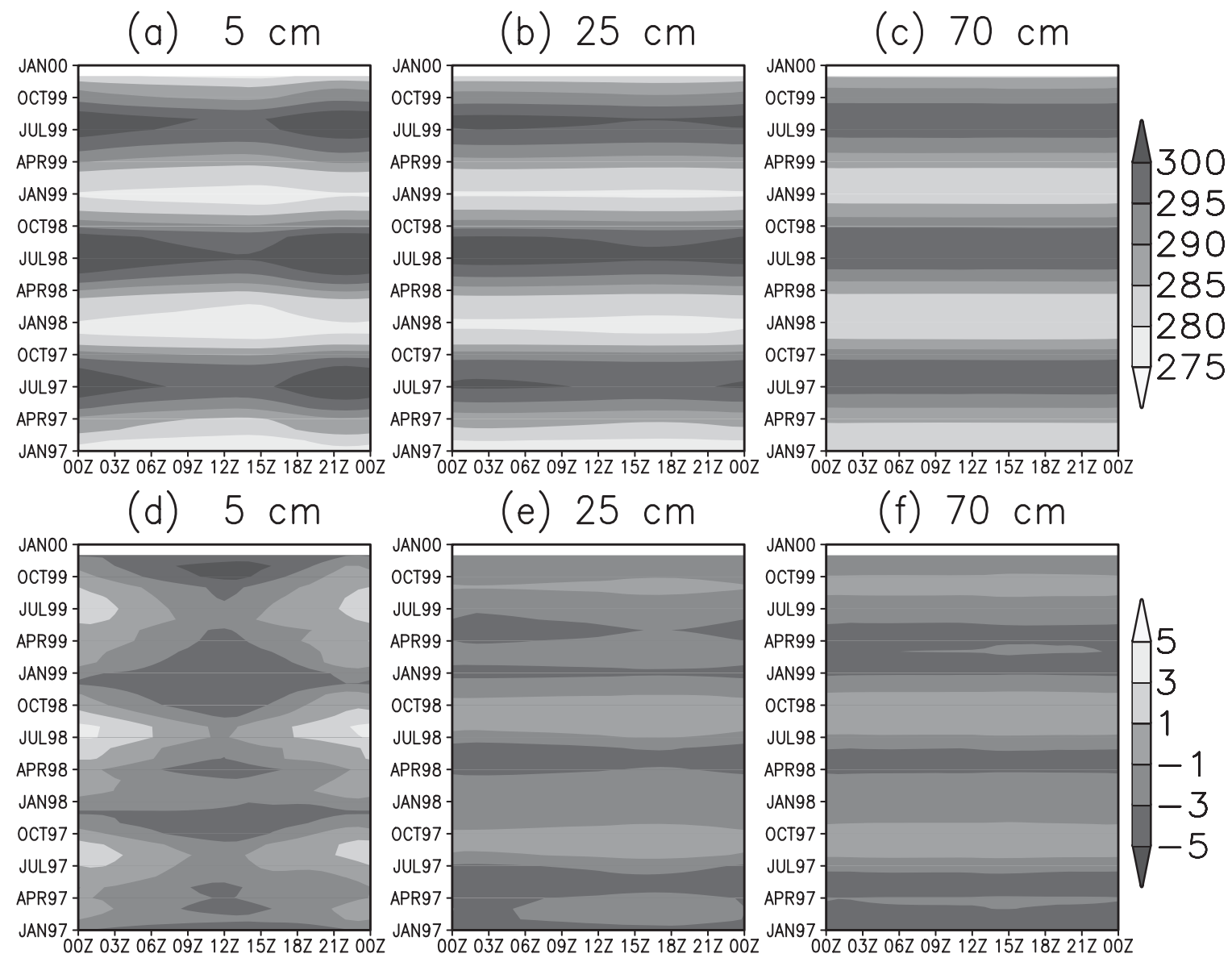

FIG. 10. Comparison of observed and simulated soil temperature for three soil layers $(0-10,10-40$, and $40-100 \mathrm{~cm})$. Time series of diurnal cycle of the observed soil temperature estimated from 72 Oklahoma Mesonet stations at (a) 5, (b) 25, and (c) $70 \mathrm{~cm}$; differences between the model and observation for Noah at the (d) first soil layer, (e) second soil layer, and (f) third soil layer.

Brock et al. (1995) noted that the shadow of the solar panel from the mesonet tower occasionally affected soil temperature reading at the $5-\mathrm{cm}$ depth. In addition, vegetation cover may have moderated the response of the soil temperature sensors. These effects resulted in measurement errors. The soil temperatures in the Noah model physically represent an average for that layer. A more strict comparison with observations therefore requires an integrated soil temperature throughout a layer rather than point measurement at a specific depth. Furthermore, soil temperature and moisture were closely related. As indicated by Robock et al. (2003), soil texture classification problems definitely contributed to soil moisture errors in the Noah model (Y. Xia et al. 2012c, manuscript submitted to J. Hydrol.). Soil moisture errors would affect the composite soil volumetric heat capacity and soil thermal conductivity used in the Noah LSM (Chen and Dudhia 2001) because heat capacity is the function of soil moisture and soil porosity and thermal conductivity is the function of soil moisture. All these errors can interact together, making this issue complex. In general, a soil moisture error of $0.1 \mathrm{~m}^{3} \mathrm{~m}^{-3}$ may lead to an error of more than $1.6 \mathrm{~K}$ for maximum or minimum daily soil temperature (Godfrey and Stensrud 2008).

It should be noted that soil texture and vegetation classification problems definitely contributed errors to Noah-simulated soil temperature as well as to Noahsimulated soil moisture (Robock et al. 2003) as they could not correctly represent the vegetation and soil texture conditions at some validation sites. In addition, the Noah model predefined vegetation conditions as a constant value by month rather by day (i.e., monthly greenness fraction, vegetation fraction), this would have also introduced errors into the Noah-simulated soil temperature. These errors were associated with misrepresentations of NLDAS vegetation and soil texture conditions, which will be addressed in a future effort.

Errors attributed to forcing data may have also contributed to the biases of Noah-simulated soil temperature. Positive summertime temperature biases in the top 10-cm 

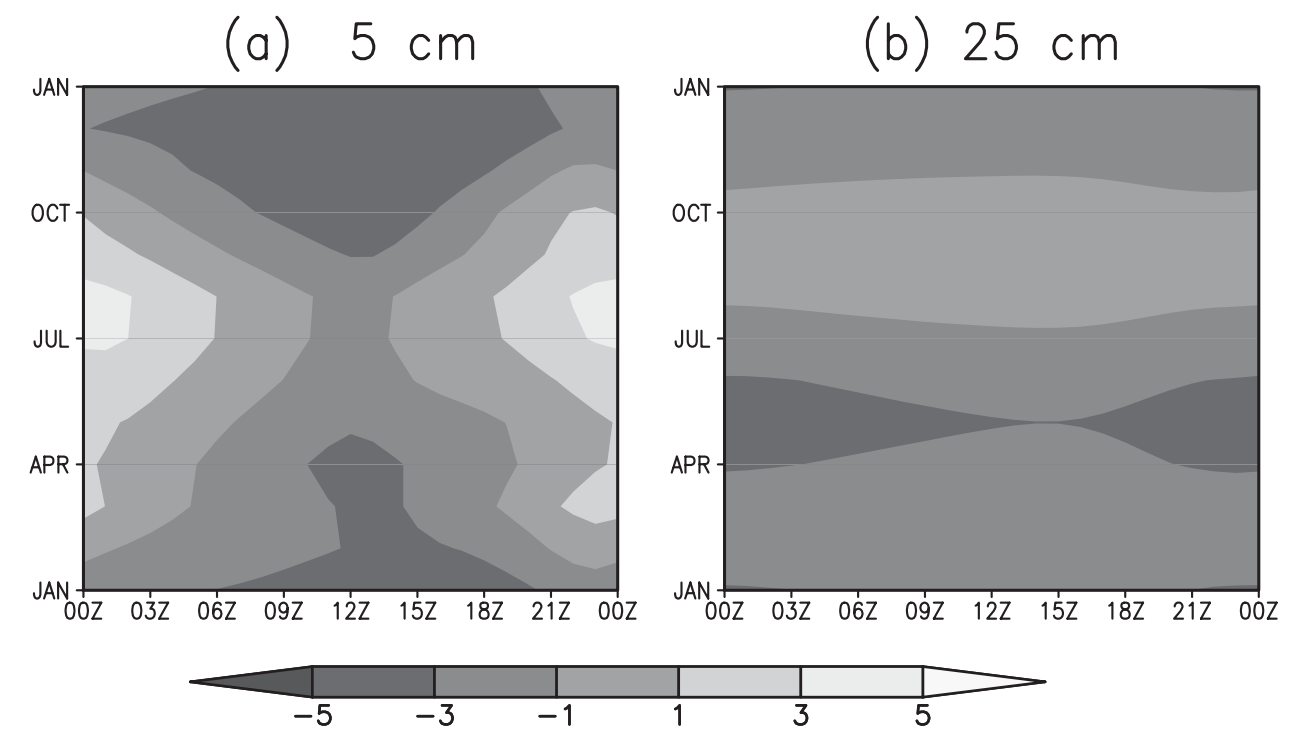

FIG. 11. Comparison of 12-yr (1999-2010) mean monthly simulated and observed diurnal cycles over Oklahoma Mesonet. Differences between Noah-simulated and observed soil temperature at (a) 0-10and (b) 10-40-cm soil layers. We used 12-yr standard soil temperature measurements over 114-127 stations over Oklahoma Mesonet for this validation.

soil layers likely stemmed from the documented excess of solar radiation during the daytime (Fig. 12a), while negative wintertime soil temperature biases may have partly resulted from underestimated downward longwave radiative fluxes during nighttime hours (Fig. 12b). The effect of model parameters on soil temperature was investigated by Robock et al. (2003), Godfrey and Stensrud (2008), and Chen et al. (2010). Model parameters such as aerodynamic conductance may have greatly affected soil temperature simulations through modifying the efficiency of surface turbulent fluxes to the atmosphere. Robock et al. (2003) indicated that a larger aerodynamic conductance can reduce the warm bias in midday skin temperature for the Noah LSM through heat loss from the land surface. This large aerodynamic conductance has been implemented to Noah LSM for NLDAS-2 run. NLDAS-1 also found that Noah LSM displayed a small snow water equivalent and early snowmelt due to large sublimation on snow surface. To reduce large sublimation, the value of the surface exchange coefficient $(\mathrm{CH})$ was modified to reflect atmospheric boundary layer stability as quantified by the Richardson number $\mathrm{Ri}_{B}$. In particular, if $\mathrm{Ri}_{B}$ is greater than 0.0 (stable conditions) but is less than or equal to $2.0, \mathrm{CH}=\mathrm{CH} \times \max [1.0-$ $\left.\left(\mathrm{Ri}_{B} / 0.5\right), 0.05\right]$. This leads smaller aerodynamic conductance for stable boundary cases, which often occurs in cold season (from late fall to early spring). This approach, called an "intermediate fix," was originally tested in polar regions (Slater et al. 2007) and U.S. western mountainous regions (Livneh et al. 2010) to reduce large aerodynamic conductance values in winter, which were generating large sublimation. This approach has improved simulation of snow water equivalent, snow cover, and other water variables related to snowpack over the western mountainous region (Livneh et al. 2010). At present, this was implemented within the Noah LSM for NLDAS-2 for all stable cases. However, this approach produced erroneously small aerodynamic conductance values such that little sensible heat was transferred to the land surface from the atmosphere. This implementation resulted in colder nighttime skin temperatures $(1-3 \mathrm{~K})$ than in the original version of Noah over winter (Fig. 13). In the test, the same version of Noah as NLDAS-2 was used except that the intermediate fix approach was removed. The results show that this approach contributed to part of a $3-5-\mathrm{K}$ negative bias in simulating skin temperature when compared with the observations during the nighttime in winter (Fig. 12c). The other part of the 3-5-K negative bias in simulating skin temperature may have come from the other error sources mentioned above. Since surface skin temperature has a close relationship with upper-layer soil temperature and ground heat flux, the cold bias for skin temperature will no doubt have affected the soil temperature in the shallow soil layer (i.e., $0-10 \mathrm{~cm}$ ). The error in simulated soil temperature for the top soil layer would have spread to soil temperature in deeper soil layers via heat conduction processes, although the differences between Noah-simulated and observed ground heat flux were small (Fig. 12d). The sensitivity tests show 

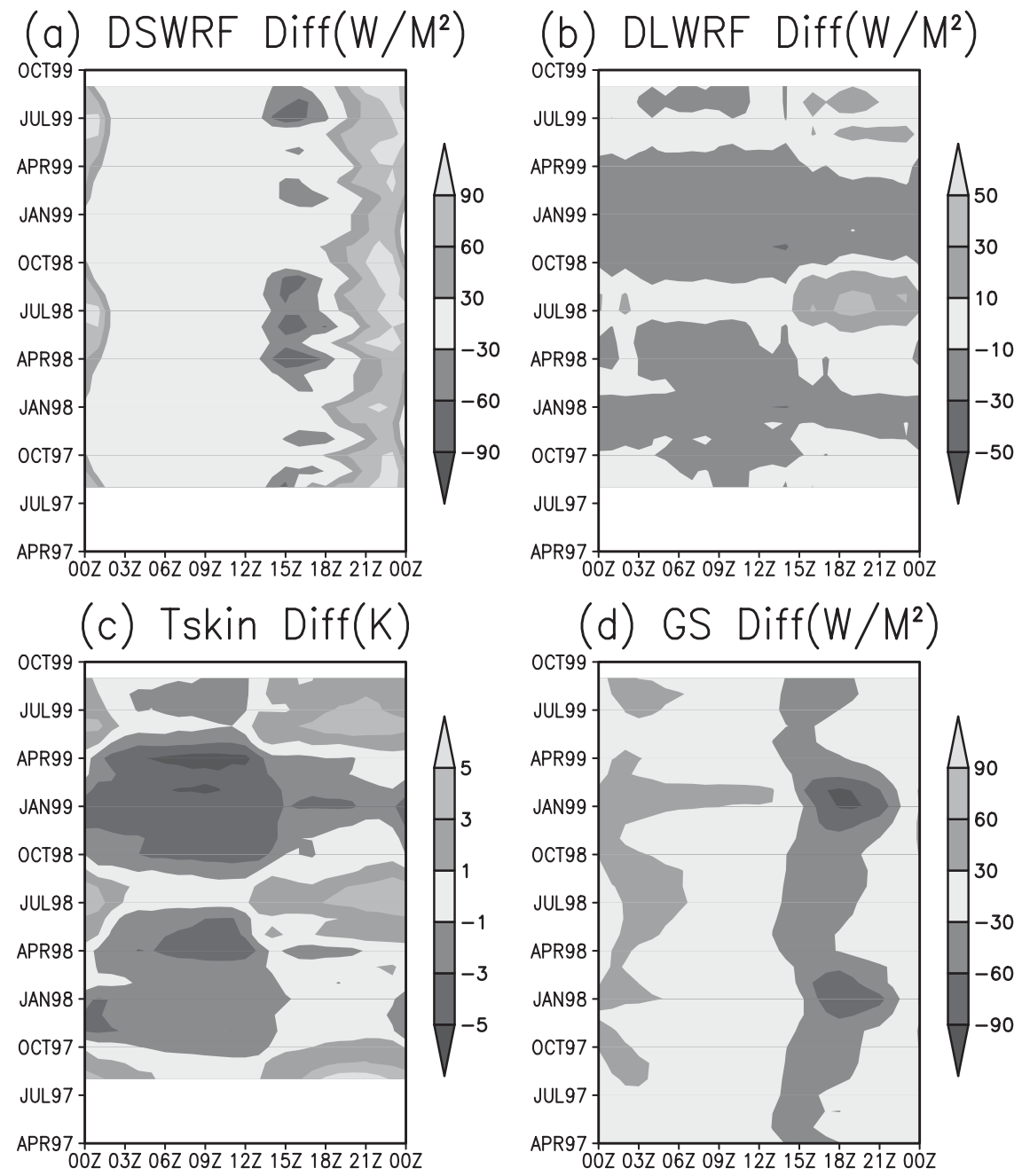

FIG. 12. Difference between Noah-simulated and observed monthly mean diurnal cycles of (a) downward shortwave radiation (DSWRF) $\left(\mathrm{W} \mathrm{m}^{-2}\right)$, (b) downward longwave radiation (DLWRF) $\left(\mathrm{W} \mathrm{m}^{-2}\right),(\mathrm{c})$ radiative skin temperature Tskin $(\mathrm{K})$, and (d) ground heat flux GS $\left(\mathrm{W} \mathrm{m}^{-2}\right)$. Positive difference indicates a stronger downward shortwave and longwave radiation, and downward heat flux for DSWRF, DLWRF, and GS, respectively.

that model-simulated soil temperatures were closer to observations when a $1-3-\mathrm{K}$ negative bias led by the fix approach was removed (Figs. 14a-c). Therefore, this intermediate fix approach improved snowpack simulation, while it deteriorated skin temperature and soil temperature simulations when compared with observations. To solve this issue, more studies into how to use the intermediate fix approach to improve both snowpack and soil temperature simulation (i.e., conditioned by snow cover and/or snow water equivalent) will be addressed in a future paper.

Acknowledgments. Author YX is supported by Climate Program Office (CPO) Modeling, Analysis, Predictions, and Projections (MAPP) program. The authors thank the entire Oklahoma Mesonet team for their dedication to collect and measure soil temperature data. We also thank the U.S. Department of Energy (DOE) Atmospheric Radiation Measurement and Oklahoma Mesonet programs for providing the ARM/CART and Oklahoma Mesonet meteorological, heat flux, and soil data that were provided to the project at no cost. The Oklahoma Mesonet Program is supported by the State of Oklahoma. This research would not have been possible without these measurements. The support to $\mathrm{MH}$ for processing the long-term soil temperature dataset from the ARM archive is provided by DOE's Atmospheric System Research (ASR) program. PNNL is operated for the DOE by Battelle Memorial Institute under Contract DE-AC06-76RLO1830. 
(a) Test-OBS

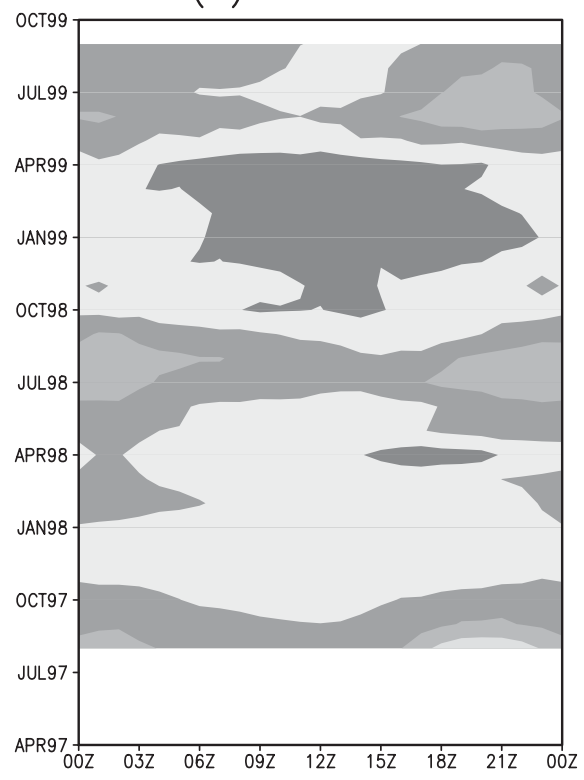

(b) Noah -Test

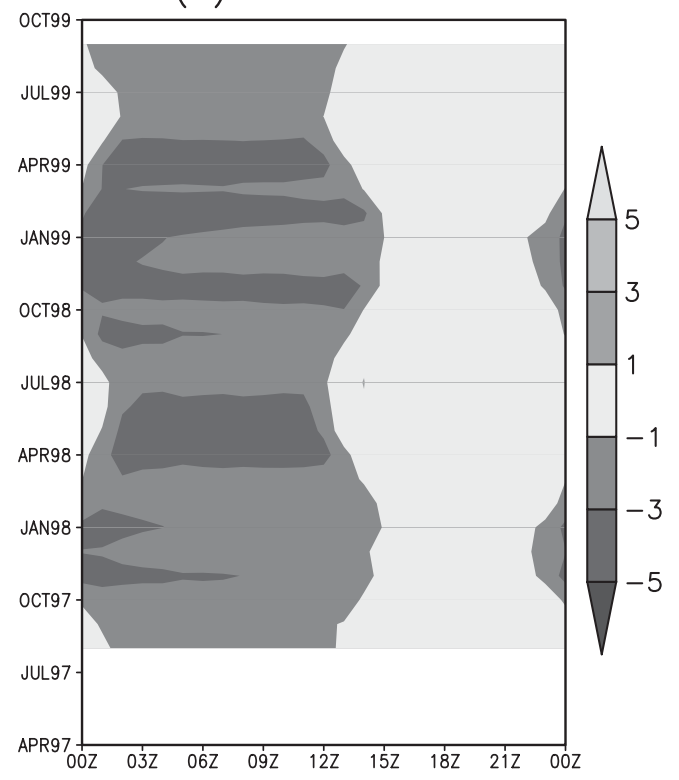

FIG. 13. (a) Difference between simulated (Test) and observed monthly mean diurnal cycles of radiative skin temperature Tskin (K), and (b) difference between skin temperature simulated from NLDAS Noah and sensitivity test (test).

\section{APPENDIX}

\section{A Long-Term Hourly Soil Temperature Dataset from the Oklahoma Mesonet}

The Oklahoma Mesonet (Brock et al. 1995; Illston et al. 2008; McPherson et al. 2007) is an Oklahoma-wide network of meteorological stations (Fig. A1). The network provides observations of air temperature, relative humidity, wind speed, wind direction, barometric pressure, precipitation, soil temperature (5-, 10-, and 30-cm depths), solar radiation, and soil moisture, which are archived by the Oklahoma Mesonet and the External Data Center (XDC) of the DOE ARM Climate Research Facility (http://www.archive.arm.gov), to enhance the capability of the ARM data archive for supporting climate and Earth system research.

As pointed out by Holmes et al. (2012), the soil temperature observations from the Oklahoma Mesonet are one of the few datasets that meet most of the requirements for robust assessment of the soil temperature simulations from numerical weather prediction models, which serve as a dynamic ancillary resource for next-generation soil moisture retrievals from L-band (1.4 GHz) satellites such as the NASA Soil Moisture
Active Passive (SMAP) mission. Such observations are also crucial for evaluating simulations from climate and Earth system models as discussed in the introduction section of this paper.

In the Oklahoma Mesonet, the soil temperature at each location is measured with thermistor probes installed horizontally at depths of $0.05,0.1$, and $0.3 \mathrm{~m}$ under native sod and at depths of 0.05 and $0.1 \mathrm{~m}$ under bare soil. The sampling rate of the sensors is $30 \mathrm{~s}$, but the 15-min averages are reported with an accuracy of $0.5 \mathrm{~K}$ for a temperature range from -30 to $55 \mathrm{~K}$. Various automated and manual quality control checks are performed by the Oklahoma Mesonet, including a site visit at least three times per year (Shafer et al. 2000).

To generate the long-term hourly soil temperature dataset used in this study, we further processed the 15-min records at 114-127 stations during the period of 1999-2010 from the ARM archive by removing "bad" data points and obvious spikes (i.e., $> \pm 3$ standard deviations departure from the mean diurnal cycle in any given month) and aggregating to an hourly time step. Missing data values at the hourly time step are flagged for any further processing as needed in intended applications. 
(a) $5 \mathrm{~cm}$

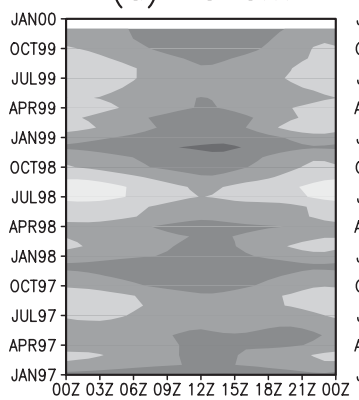

(d) $5 \mathrm{~cm}$

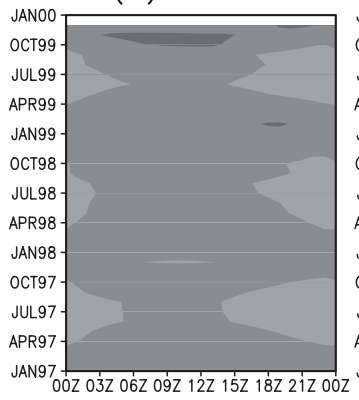

(b) $25 \mathrm{~cm}$

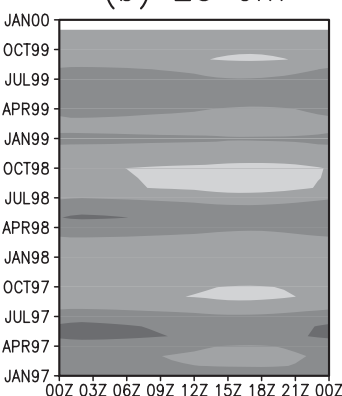

(e) $25 \mathrm{~cm}$

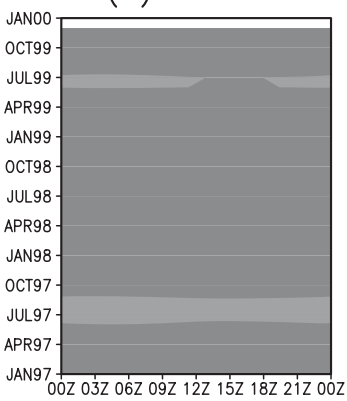

(c) $70 \mathrm{~cm}$

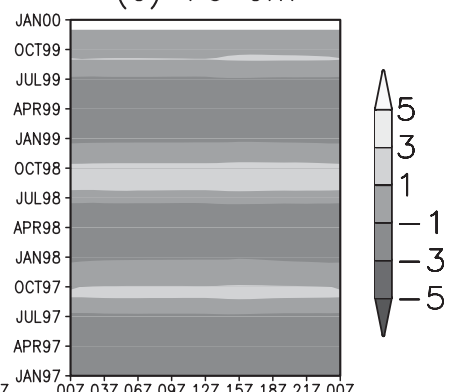

FIG. 14. Comparison between simulated and observed soil temperature diurnal cycle for three soil layers $(0-10,10-40$, and $40-100 \mathrm{~cm})$. Difference between simulated (Test) and observed soil temperature at (a) 5, (b) 25, and (c) $70 \mathrm{~cm}$; differences between soil temperature simulated from NLDAS Noah and sensitivity test (Test) at the (d) first soil layer, (e) second soil layer, and (f) third soil layer.

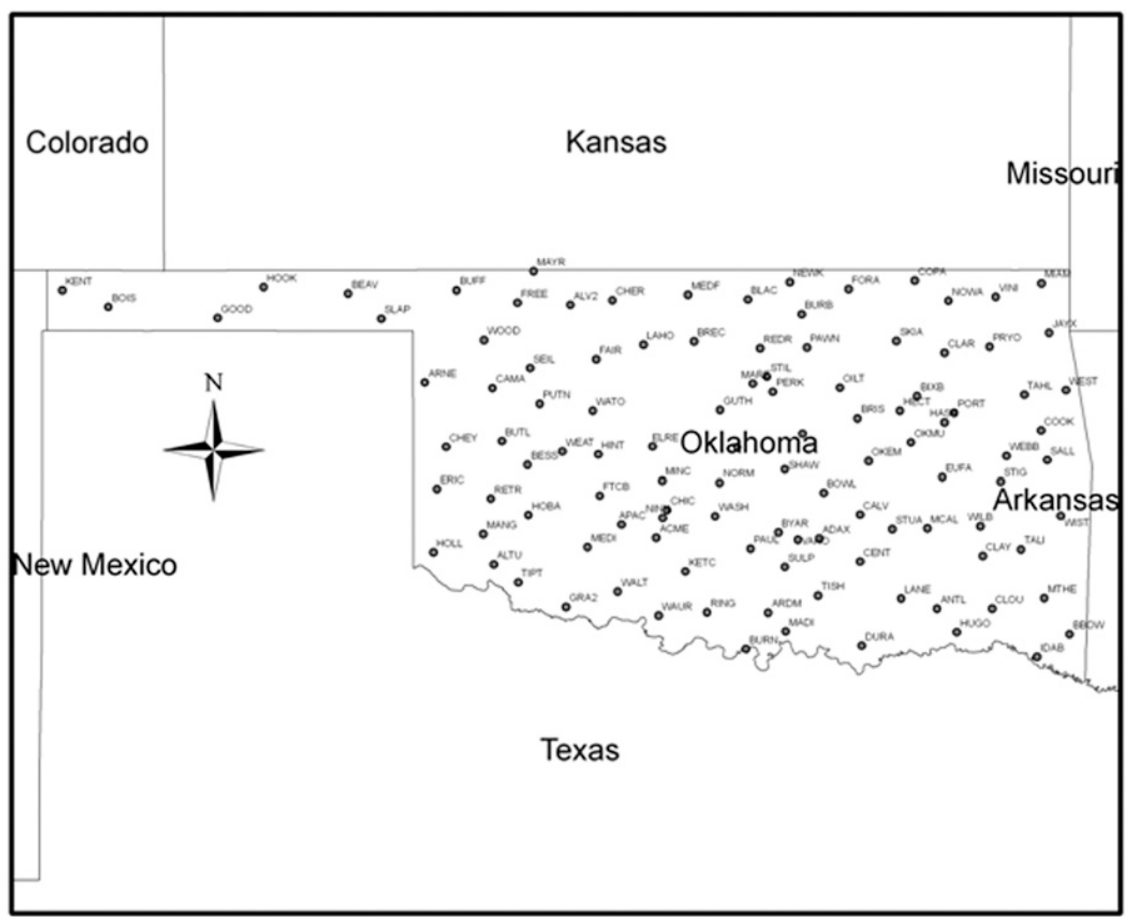

FIG. A1. Distribution of active soil temperature stations in the Oklahoma Mesonet in all years between 1999 and 2010. 


\section{REFERENCES}

Avissiar, R., and P. A. Pielke, 1989: A parameterization of heterogeneous land surfaces for atmospheric numerical models and its impact on regional meteorology. Mon. Wea. Rev., 117, 2113-2136.

Berg, A. A., J. S. Famiglietti, J. P. Walker, and P. R. Houser, 2003: Impact of bias correction to reanalysis products on simulations of North American soil moisture and hydrological fluxes. J. Geophys. Res., 108, 4490, doi:10.1029/2002JD003334.

Betts, A. K., J. H. Ball, A. C. M. Beljaars, M. J. Miller, and P. A. Viterbo, 1996: The land surface-atmosphere interaction: A review based on observational and global modeling perspectives. J. Geophys. Res., 101 (D3), 7209-7225.

Brock, F. V., K. C. Crawford, R. L. Elliott, G. W. Cuperus, S. J. Stadler, H. Johnson, and M. D. Eillts, 1995: The Oklahoma Mesonet: A technical overview. J. Atmos. Oceanic Technol., 12, 5-19.

Chen, F., and J. Dudhia, 2001: Coupling and advanced land surface-hydrology model with the Penn State-NCAR MM5 modeling system. Part I: Model implementation and sensitivity. Mon. Wea. Rev., 129, 569-585.

Chen, Y., K. Yang, D. Zhou, J. Qin, and X. Guo, 2010: Improving the Noah Land Surface Model in arid regions with an appropriate parameterization of the thermal roughness length. J. Hydrometeor., 11, 995-1006.

Crow, W. T., and E. F. Wood, 1999: Multi-scale dynamics of soil moisture variability observed during SGP97. Geophys. Res. Lett., 26, 23-26.

Daly, C., R. P. Neilson, and D. L. Philips, 1994: A statisticaltopographic model for mapping climatological precipitation over mountainous terrain. J. Appl. Meteor., 33, 140-158.

Dirmeyer, P. A., F. J. Zeng, A. Ducharne, J. C. Morrill, and R. D. Koster, 2000: The sensitivity of surface fluxes to soil water content in three land surface schemes. J. Hydrometeor., 1, 121-134.

Ek, M. B., K. E. Mitchell, Y. Lin, E. Rodgers, P. Grunman, V. Koren, G. Gayno, and J. D. Tarpley, 2003: Implementation of Noah land surface model advances in the National Centers for Environmental Prediction operational mesoscale Eta Model. J. Geophys. Res., 108, 8851, doi:10.1029/2002JD003296.

Entin, J., A. Robock, K. Y. Vinnikov, S. Qiu, V. Zabelin, S. Liu, A. Namkhai, and T. Adyasuren, 1999: Evaluation of Global Soil Wetness Project soil moisture simulations. J. Meteor. Soc. Japan, 77, 183-198.

,,,--- S. E. Hollinger, S. Liu, and A. Namkhai, 2000: Temporal and spatial scales of observed soil moisture variations in the extratropics. J. Geophys. Res., 105, 11 865-11 877.

Fan, X., 2009: Impacts of soil heating condition on precipitation simulations in the Weather Research and Forecasting model. Mon. Wea. Rev., 137, 2263-2285.

Fan, Y., H. M. Van Den Dool, D. Lohmann, and K. Mitchell, 2006: 1948-98 U.S. hydrological reanalysis by the Noah Land Data Assimilation System. J. Climate, 19, 1214-1237.

Godfrey, C. M., and D. J. Stensrud, 2008: Soil temperature and moisture errors in operational Eta Model analysis. J. Hydrometeor., 9, 367-387.

Hillel, D., 1980: Fundamental of Soil Physics. Academic Press, $413 \mathrm{pp}$.

Holmes, T. R. H., T. J. Jackson, R. H. Reichle, and J. B. Basara, 2012: An assessment of surface soil temperature products from numerical weather prediction models using ground-based measurements. Water Resour. Res., 48, W02531, doi:10.1029/ 2011WR010538.
Hu, Q., and S. Feng, 2002: Quality control for USDA NRS SM-ST network soil temperatures: A method and a dataset. J. Appl. Meteor., 41, 607-619.

$\longrightarrow$, and —, 2003: A daily soil temperature dataset and soil temperature climatology of the contiguous United States. J. Appl. Meteor., 42, 1139-1156.

$\longrightarrow$, and - 2004: A role of the soil enthalpy in land memory. J. Climate, 17, 3633-3643.

Illston, B. G., J. B. Basara, C. A. Fiebrich, K. C. Crawford, E. Hunt, D. K. Fisher, R. Elliott, and K. Humes, 2008: Mesoscale monitoring of soil moisture across a statewide network. J. Atmos. Oceanic Technol., 25, 167-182.

Kirschbaum, M. U. F., 1995: The temperature dependence of soil organic matter decomposition, and the effect of global warming on soil organic C storage. Soil Biol. Biochem., 27, 753-760.

Koster, R. D., and M. J. Suarez, 2003: Impact of land surface initialization on seasonal precipitation and temperature prediction. J. Hydrometeor., 4, 408-423.

— P. A. Dirmeyer, Z. Guo, and GLACE Team, 2004: Regions of strong coupling between soil moisture and precipitation. Science, 305, 1138-1140.

Liang, X., D. P. Lettenmaier, E. F. Wood, and S. J. Burges, 1994: A simple hydrologically based model of land surface water and energy fluxes for GCMs. J. Geophys. Res., 99, 14 41514428.

Livneh, B., Y. Xia, K. E. Mitchell, M. B. Ek, and D. P. Lettenmaier, 2010: Noah LSM snow model diagnostics and enhancements. J. Hydrometeor., 11, 721-738.

Mahanama, S. P. P., R. D. Koster, R. H. Reichle, and M. J. Suarez, 2008: Impact of subsurface temperature variability on surface air temperature variability: An AGCM study. J. Hydrometeor., 9, 804-815.

McMichael, B. L., and J. J. Burke, 1998: Soil temperature and root growth. HortScience, 33, 947-951.

McPherson, R. A., and Coauthors, 2007: Statewide monitoring of the mesoscale environment: A technical update on the Oklahoma Mesonet. J. Atmos. Oceanic Technol., 24, 301321.

Mesinger, F., and Coauthors, 2006: North American Regional Reanalysis. Bull. Amer. Meteor. Soc., 87, 343-360.

Pinker, R. T., and Coauthors, 2003: Surface radiation budgets in support of the GEWEX Continental-Scale International Project (GCIP) and the GEWEX Americas Prediction Project (GAPP), Including the North American Land Data Assimilation System (NLDAS) project. J. Geophys. Res., 108, 8844, doi:10.1029/2002JD003301.

Robock, A., C. A. Schlosser, K. Y. Vinnikov, N. A. Speranskaya, J. K. Entin, and S. Qiu, 1998: Evaluation of AMIP soil moisture simulations. Global Planet. Change, 19, 181-208.

_ , K. Y. Vinnikov, G. Srinivasan, J. K. Entin, S. E. Hollinger, N. A. Speranskaya, S. Liu, and A. Namkhai, 2000: The Global Soil Moisture Data Bank. Bull. Amer. Meteor. Soc., 81, 12811299.

— , and Coauthors, 2003: Evaluation of the North American Land Data Assimilation System over the southern Great Plains during warm season. J. Geophys. Res., 108, 8846, doi:10.1029/ 2002JD003245.

Shafer, M. A., C. A. Fiebrich, D. S. Arndt, S. E. Fredrickson, and T. W. Hughes, 2000: Quality assurance procedures in the Oklahoma Mesonetwork. J. Atmos. Oceanic Technol., 17, 474 494.

Slater, A. G., T. J. Bohn, J. L. McCreight, M. C. Serreze, and D. P. Lettenmeier, 2007: A multimodel simulation of pan-Arctic 
hydrology. J. Geophys. Res., 112, G04S45, doi:10.1029/ 2006JG000303.

Tindall, J. A., H. A. Mills, and D. E. Radcliffe, 1990: The effect of root zone temperature on nutrient uptake of tomato. J. Plant Nutr., 13, 939-956.

Vinnikov, K. Y., A. Robock, N. A. Speranskaya, and C. A. Schlosser, 1996: Scales of temporal and spatial variability of midlatitude soil moisture. J. Geophys. Res., 101, 7163-7174.

Xia, Y., and Coauthors, 2012a: Continental-scale water and energy flux analysis and validation for the North American Land Data Assimilation System project phase 2 (NLDAS-2): 1. Comparison analysis and application of model products. J. Geophys. Res., 117, D03109, doi:10.1029/2011JD016048.
- and Coauthors, 2012b: Continental-scale water and energy flux analysis and validation for North American Land Data Assimilation System project phase 2 (NLDAS-2): 2. Validation of model-simulated streamflow. J. Geophys. Res., 117, D03110, doi:10.1029/2011JD016051.

Xue, Y., F. J. Zeng, K. Mitchell, Z. Janjic, and E. Rogers, 2001: The impact of land surface processes on simulations of the U.S. hydrological cycle: A case study of the 1993 flood using the SSiB land surface model in the NCEP Eta regional model. Mon. Wea. Rev., 129, 2833-2860.

Zhu, J., and X.-Z. Liang, 2005: Regional climate model simulation of U.S. soil temperature and moisture during 1982-2002. J. Geophys. Res., 110, D24110, doi:10.1029/2005JD006472. 